\title{
The Importance Of Teacher/Parent Partnerships: Preparing Pre-Service And In-Service Teachers
}

Sandra B. Loughran, Dowling College, USA

\begin{abstract}
The importance of a good parent-teacher relationship has been well documented. The author presents a guide to getting parent-teacher relationships started in the right direction and then maximizing the benefits of their interactions.
\end{abstract}

Keywords: parent-teacher partnerships, early childhood education, teacher preparation

\section{INTRODUCTION}

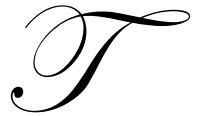

he importance of good parent-teacher relationships has been well documented. Research has shown that parent involvement in education benefits not only the child but also the parents and teachers (Eldridge, 2001). Baum \& McMurray-Schwarz (2004) found that many pre-service teachers expressed concerns about the quality of teacher-family relationships and about the role of parents in education. This article will explore the process of forming positive partnerships with parents. Several ways in which positive partnerships with parents and teachers can be fostered and made to work to meet the issues and challenges facing early childhood education will also be addressed.

The function of a good parent-teacher relationship is much more than just a vehicle for status reports from teacher to parents on a child's performance or behavior. It is really a partnership providing two-way information flow from the teacher to the parents about the child's classroom achievements and persona and from the parent to the teacher about the complementary elements in the home environment. It provides the mechanism for the teacher to invite, and support, the parents' active participation in the child's education in the home environment. And it can provide the link between classroom learning activities and at-home learning activities.

In general, parents or other prime caregivers have the best firsthand knowledge of the child. It is in the best interest of our children to take full advantage of that information as an aid in understanding and assessing a child. Knowing how children behave at home and in other contexts away from school can help teachers make wellbalanced assessments of their students. This is especially important when a child presents behaviors or conditions that may indicate special needs.

Communication with parents is of paramount importance. Teachers need to be prepared to work with a diversity of caregivers, from working parents to nannies or relatives. Communicating with the prime caregiver is often complex. Our lives are impacted by a very fast paced world and children are caught in the middle. Although they are surprisingly resilient and can roll with the punches, the fast pace takes its toll on them, their parents, and also on their teachers. In an early childhood setting, a teacher usually sees some parents more than others, but all parents need and want to know what is going on with their child.

Because of the diversity among parents and to best communicate with each parent, it is necessary to:

- $\quad$ communicate succinctly and clearly. Organize your thoughts ahead of time, review written messages.

- make clear to each one that he or she is respected and his or her participation is encouraged 
- $\quad$ be flexible, encouraging working parents to participate actively and be involved when and where possible

Teachers need to respect and acknowledge the parents' role as prime educators and role models. The more teachers encourage parents in this role, the more the child will benefit, and the more fruitful classroom learning will become. In this climate of respect, teachers can offer suggestions for carrying over concepts from the classroom to the home so that what is learned in school has an impact on the time parents spend with the children. It is incumbent on teachers to establish a classroom-home link or bridge.

For example, teachers can:

- $\quad$ suggest books to be read at home or possible activities to do on weekends

- $\quad$ send home short articles on developmentally appropriate activities found in newsletters or articles

- $\quad$ let children take home books that they make at school. Books can be made with the children, about field trips or themes developed at school. These books can be made from the children's drawings or paintings with their words dictated to the teacher. If possible have the books laminated. Children can take turns bringing them home

- $\quad$ send home weekly or monthly newsletters to help bridge the connection between home and school. This will give parents a sense of the teacher's expectations of the children and of their endeavors with the children.

These activities can provide a bridge between home and classroom because children often do not elaborate at home about what goes on at school. It is the teacher's job to fill in the blanks for their parents.

In order to build and develop a relationship of trust, a teacher's first contacts with parents are crucial. Remember first impressions are lasting impressions. A relatively simple action; contacting each parent during the first week of school, to let parents know how their child is adjusting, can set the stage for a year of communication and collaboration. Following up with a phone call after a concerned parent has contacted you confirms to that parent that the teacher and the school care, and have listened to their concerns.

Contact can begin even before the first day of class. Contacting parents prior to the opening of school will also set the stage for communication. Asking each parent to write and send a letter describing their child helps teachers gain insight into the child, the parent/child relationship, and the parent's expectations and concerns.

Many parents are reticent to ask questions, but some want the teacher's undivided attention, almost daily, which simply isn't feasible or appropriate. Parent/teacher relationships are about the child, not about the needs of adults, either teacher or parent. Attaining this balance can be difficult, but teachers must arrange ways that parents can feel free to contact them without disrupting classroom routines.

Teachers can, for example, encourage parents to phone or email at specific times of day. As for responding, most teachers find that face-to-face conferences work best, especially when sensitive matters are concerned. The written word can often be mistaken or misunderstood. Parents and teachers do best when they can see the whites of one another's eyes.

One of the most important elements in establishing a good relationship with a parent is by demonstrating, very early, that the teacher really knows the child. Observation is key. It is a skill that every educator has to nurture and refine.

Observation, in the form of anecdotal records for each child, is a powerful tool to have when working with parents. Although it is difficult to continually jot down notes in the course of the day, there are a number of ways to maintain an accurate record about each child and still keep the classroom moving. Some examples are: 
- $\quad$ Keep a loose-leaf notebook with a section set aside for each child in the class.

- $\quad$ Have scraps of paper or address labels handy for jotting down notes during the day - you can keep them in your pocket or a desk drawer for easy access.

- $\quad$ Record notable behaviors and moments when they happen and date them. You don't have to write something down about each child every day - just when something notable happens

- $\quad$ Review the entries each week.

At the end of a week or month you will have a detailed running record on each child. Not only does this practice help to guide and individualize the curriculum, but it also provides an accurate historical record of all the children that can be of tremendous help when conferring with parents.

I once heard a Montessori trainer introduce some Montessori tenets to a group of nursery school teachers. She told them that each night before she went to bed she would go over, in her mind, the children in her class, name by name. She would then make it a point to note the last name she remembered and then to interact with that child first thing the next day. In other words, because that child did not stand out in her memory of the day, she knew she needed to spend more time with him or her. This emphasizes how important it is for teachers to individualize their classes. Each child needs quality time with the teacher, however it is apportioned. Record keeping, and other simple methods such as the technique described above can ensure that this quality time actually takes place.

Conferences are another very important communication tool for teachers and parents, and the first conference is a critical one. When we confer, we inform parents and parents inform us. Conferences often get off to a productive start when teachers ask parents how things are going. Teachers can get a good feel for what is happening with the child at home and gain insight into how parents feel about what is going on at school. When it's the teacher's turn to speak, begin by talking about the child's strengths, drawing on specifics from the anecdotal information you've collected. First and foremost, let parents know that you know and appreciate their child. Finally, discuss any concerns. And no matter how strong your concerns may be, don't flag them as "problems." Use the word "concern" or say, "I've noticed such and such." This way, parents won't panic. At the same time, make sure that by the end of the conference all the cards are on the table so you can begin to sort out what's next for the child.

All of the suggestions offered, to this point, are intended to get the parent-teacher relationship started in the right direction. Granted, it doesn't always run as smoothly as all this, but if you make the early effort, at least the homework is done. Now comes time to practice the skills of diplomacy and genuine concern, a process that is never completely finished. Here is where the relationship really begins and, if successful, will prove to be worth all the effort.

When teachers and parents work as partners, the good they can do for children is virtually limitless. Some of the major issues that demand both parent / teacher collaboration include the following:

Parents need to be supported as they raise their children. No parent today is immune to societal pressures from the media and elsewhere to accelerate their children in many different ways. The competition for getting into the proper schools and performing at the top of every scale has never been more demanding. David Elkind's book, The Hurried Child (1993) rings true today. We are pushing children to grow up too fast. We are badgering them to master some skills much too early. In so doing, we are frustrating them, and ourselves. For many parents it means putting more pressure on their already overstressed lifestyle.

As early childhood educators and advocates, we need to keep childhood alive. How do we do that?

First of all, value play and keep it in the curriculum. Even the most educated parents oftentimes misunderstand the place that play has in the child's cognitive as well as their social, emotional, and physical development. Teachers can educate parents about this by sending home short but informative articles. Parents will be relieved to learn that they can stop pushing their children and simply enjoy them. Similarly, teachers can send newsletters home which contain the rationale for projects and thematic work being worked on in school. A teacher 
can explain the skills for reading and math readiness. Parents often aren't aware of those connections and appreciate when they are pointed out.

Provide a language rich environment and nurture the love of books. This is the best way to prepare for reading readiness and to teach reading to preschoolers. Young children don't need dittos, which often turn them off to the process before they even begin. Studies show (Hart \& Risley, 2003) that the number of verbal interactions between parent and child almost without exception has a huge impact on a child's literacy. Teachers and schools can try to fill in the gaps, but parents hold the greatest power. Teachers can help parents by suggesting ways to positively reinforce children who are learning to read, and to suggest appropriate readings and workshops. Teachers can also suggest specific books since many parents are not well-versed in children's literature. Book clubs through publishers for preschoolers usually have many of the classics in paperback or hardback for very reasonable prices. Teachers may want to emphasize or recommend some books more than others. When parents ask for "homework" for their four-year-old, teachers can reiterate that the best thing that the parent can do is to read the child a book or have the child "read"/tell the story to them.

Encourage creativity. With all the wonderful media and materials for expression that are at a child's fingertips, we need to challenge them to be imaginative and become problem solvers. We can model that by emphasizing how unique a child's work of art is rather than looking for and rewarding perfection. Frame some of the child's paintings or drawings before sending them home. Prepare the parents for this opportunity to show appreciation for a child's efforts. (Send home a few refrigerator magnets!)

Help parents to understand assessment as opposed to testing. There is no question that we need and want to be accountable for our work and time with youngsters. However, testing preschoolers is not the most productive way of assessing them. It can be counter-productive and misleading. Readiness for elementary school is a process. A teacher can help parents realize the importance of the steps in the process. By doing this everyone can celebrate the conquests along the way to success in school. Parents can then be informed advocates when their child is having difficulties in school.

Early intervention is a gift to a child who presents special needs. Education has made great strides with legislation that entitles a child to get services, where needed, from birth on. As educators we need to be cautious but vigilant for those children who can profit from these services. This is often very difficult because children are growing and developing at such different rates. We need to be aware of the different alerts that a child may present. And this is an area where working with parents is extremely sensitive.

\section{CONCLUSION}

These are just a few of the many avenues for teachers to connect with parents. Educators must keep in mind that they are serving the child, and focus on what is best for that child. A good working partnership between teacher and parent is essential to giving a child your best. The preceding ideas and suggestions for starting off on the right foot are those of an educator. But let me finish with one thought as a parent: I believe that every parent very much wants to know that you, as a teacher 1) knows their child and 2) first and foremost, likes their child. This is where the parent/teacher relationship really begins.

\section{REFERENCES}

1. Baum, A.C., and McMurray-Schwarz, P. (2004). Preservice teachers' beliefs about family involvement: Implicatons for teacher education. Early Childhood Education Journal, 32 (1), 57-61.

2. $\quad$ Eldridge, D. (2001). Parent involvement: it's worth the effort. Young Children, 56 (4), 65-9.

3. Elkind, D. (2001). The hurried child: Growing up too fast too soon. $\left(3^{\text {rd }}\right.$ Ed.). Cambridge, MA: Da Capo Press.

4. Hart, B., and Risley, T.R. (2003). The early catastrophe: the 30 million word gap. American Educator, 27 (1), 4-9. 